\title{
Solvent used in extraction process of agarwood: a systematic review
}

\author{
Zakaria, F., *Talip, B.A., Kahar, E.E.M., Muhammad, N., Abdullah, N. and Basri, H. \\ Faculty of Applied Sciences and Technology, Universiti Tun Hussein Onn Malaysia Kampus Pagoh, KM 1, \\ Jalan Panchor, 84600, Panchor, Johor, Malaysia
}

\begin{abstract}
Article history:
Received: 2 October 2019

Received in revised form: 2 December 2019

Accepted: 6 December 2019

Available Online: 4 January 2020
\end{abstract}

\section{Keywords:}

Agarwood,

Extraction method,

Extraction solvents,

Bioactive compounds

\section{DOI:}

https://doi.org/10.26656/fr.2017.4(3).333

\begin{abstract}
The method of extraction of Agarwood is usually dependent on the purpose of the extract. This systematic review aims to look at the number of studies that use different types of solvents in the process of extraction. There are 3 types of solvents commonly used in the extraction of agarwood essential oils namely methanol, ethanol and water. Each solvent produces different extracts in terms of quantity and quality of the final product. However, there is controversy over the use of solvents as it may cause a cytotoxic effect on the user. Another common type of solvent is water. Although water is a cheap solvent and relatively safe, aqueous extracts have more impurities that make isolating the desired compound difficult. After the extraction process, the crude extract was fractionated into the desired compounds and this technique is widely applied, especially in the whole process of extraction of the agarwood. In conclusion, extraction solvents have certain advantages and disadvantages, and this is one of the reasons why this extraction method depends on the purpose of using the final product such as agarwood essential oil.
\end{abstract}

\section{Introduction}

Agarwood is a highly valuable product obtained from the trunk and root of the Aquilaria and Gyrinops tree species from the family of Thymalaeaceae. Agarwood also called as gaharu, aloeswood, agalloch, eaglewood, oud, oudh, kyara, chen xiang, tomention, kalambak, jinkoh, or kanankoh in different regions is a fragrance non-timber product origin from tropical rainforest in Asia. All part from agarwood plants including stem, skin, leaves, flowers, fruits and twigs have been used from ancient times to produce perfume products, medicines, green tea and cosmetics.

The Aquilaria leaves have great potential in medicinal purposes. Several studies have been done to evaluate the effects of the leaves extracts to health. Traditionally, Aquilaria leaves were used to treat toothache, colic, severe headache, rheumatism and pains during pregnancy due to the presence of alkaloid in the extract (Khalil et al., 2013). It also possesses laxative effects (Hara et al., 2008; Kakino et al., 2010a; Kakino et al., 2010b), antihyperglycaemic activity (Pranakhon et al., 2011), antioxidant and antibacterial activities (Hendra et al., 2016).

Normally, the fragrant agarwood resin did not form in healthy wood tissues unless there is a bacterial infection, chemical stimulations, physical wounding and insect attack (Okudera and Ito, 2009). The agarwood resin which contains secondary metabolites is produced as the self-protection to the action. The bioactive compounds or phytochemicals in the agarwood tree is a part of its defense mechanism against any attack either from environmental factors or diseases (Barden et al., 2000). Essential oils are the most interesting product which can be extracted from infected Aquilaria tree and contribute to economy. First-grade agarwood is one of the most expensive natural raw materials in the world. Resin and essential oil from three species of agarwood plant, namely Aquilaria malaccensis (agallocha), $A$. crassna, and $A$. sinensis have been widely explored for their phytochemicals.

CITES (Convention on International Trade in Endangered Species of Wild Fauna and Flora) has listed that the agarwood plant or Aquilaria species (Thymelaeaceae) in Appendix II as an endangered species due to their declining numbers in its natural environment. One of the factors that led to this situation was due to unrestrained cuts by humans.

Various techniques have been used in extracting different parts of agarwood, including water distillation or hydrodistillation, steam distillation, solvent extraction and supercritical fluid extraction (Naef, 2011). 
Agarwood is mainly extracted for its expensive essential oil whereas other parts of the plant were extracted for pharmacological purposes. Sanskrit text has mentioned that agarwood as an aromatic product since 1400 B.C.E. In 65 B.C.E., Dioscorides, a first-century Greek physician, botanist and pharmacologist has described the use of agarwood extracts in medicine (López-Sampson and Page, 2018). Agarwood has been used as an ethnomedicine in countries in Southeast Asian, China and Bangladesh for joint pain, inflammatory-related ailments, and diarrhea. Addition on that, several studies also report on the ability of agarwood as a stimulant, sedative and cardio-protective agent. Traditionally used of agarwood did not emphasized on the bioactive compounds extracted from agarwood but only the effects on health. The use of agarwood traditionally does not emphasize on the agarwood bioactive compounds but rather expresses its effect on health.

To date, studies related to agarwood are mainly focused on beneficial compounds for health (Hashim et al., 2016), volatile and semi-volatile constituents (Naef, 2011), quality assessment and grading of agarwood (Ismail et al., 2015; Liu et al., 2017), agarwood oil quality analysis (Ismail et al., 2014) and induction technology (Azren et al., 2019). In spite of this, there are limited studies have described on the extraction technique. Therefore, this systematic review aims to gather information about the extraction techniques involves in different parts of the agarwood plant and the purposes of the extraction.

\section{Materials and methods}

The method used to retrieve articles related to extraction of agarwood is PRISMA which includes resources from the Scopus database. Scopus e-database is used to run the systematic literature review, eligibility and exclusion criteria, steps of the reviewing process (identification, screening, eligibility) and data abstraction and analysis.

\subsection{PRISMA}

The review was performed by following the Preferred Reporting Items for Systematic Reviews and Meta-Analyses (PRISMA) Statement.

\subsection{Resource}

The review depends on the journal database from Scopus only (Figure 1). The Scopus database was selected because the database is organized by independent experts from various fields including science, technology and medicine and also social sciences, arts and humanities. It contains more than
23,500 peer-reviewed journals, 8.5 million Open Access articles other than books and conference proceedings. Thus the database is reliable and sufficient to provide the information required in this review.

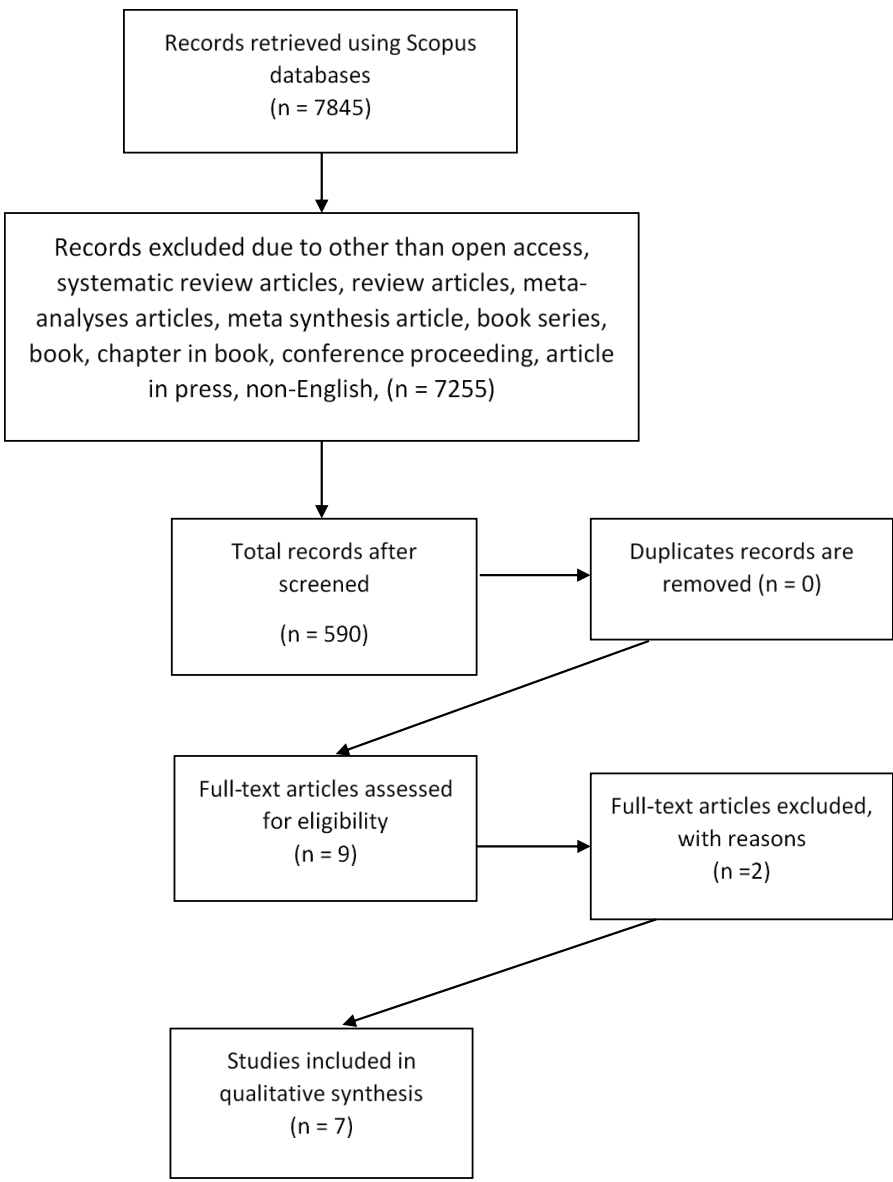

Figure 1. Flow diagram for systematic review of extraction methods used in agarwood

\subsection{Systematic review process}

\subsubsection{Identification}

The process of review was performed in May 2019. The systematic review process comprises of four stages. The first stage is identification, which is the most crucial step where the keywords used in the search process need to be identified based on previous study and thesaurus. Keywords similar and related to the extraction, agarwood, their species and scientific names were used (Table 1).

Figure 1. Flow diagram for systematic review of extraction methods used in agarwood

\begin{tabular}{ll}
\hline Database & Keywords used \\
\hline & TITLE-ABS-KEY ( "extraction*" OR \\
& "distillation*" OR "plant extract*" OR "essence" \\
& OR "distillat*" "concentrat*" OR "infusion*" ) \\
& AND ( "agarwood*" OR "oud*" OR "gaharu*" \\
Scopus & OR "agilawood" OR "agalloch" OR "aloeswood" \\
& OR "eaglewood" OR "jinko" OR "aquilaria \\
maleccensis" OR "aquilaria brachyantha" OR \\
"aquilaria hilata" OR "aquilaria microcarpa" OR \\
"aquilaria rostrata" )
\end{tabular}




\subsubsection{Screening}

In this review, only article journals with empirical data and review article are selected (Table 2). Other types of references such as book, chapter in book, book series and conference proceeding are all eliminated. Non -English publications also were excluded, and the review limits to English articles only to avoid any difficulty in understanding the research articles. With regard to the timeline, the latest five years published articles were selected which from the year 2015 to 2019 .

Table 2. The inclusion and exclusion criteria

\begin{tabular}{lll}
\hline \multicolumn{1}{c}{ Criterion } & \multicolumn{1}{c}{ Eligibility } & \multicolumn{1}{c}{ Exclusion } \\
\hline \multirow{2}{*}{ Literature type } & $\begin{array}{l}\text { Journal (research } \\
\text { article) }\end{array}$ & $\begin{array}{l}\text { Book, chapter in the book, } \\
\text { review, book series and con- } \\
\text { ference proceeding }\end{array}$ \\
Language & English & $\begin{array}{l}\text { Non-English } \\
\text { Timeline }\end{array}$ \\
\hline
\end{tabular}

\section{Results and discussion}

All the studies involved in this review used the solvent extraction method to separate the desired natural products from the raw material. There are many procedures to recapture selected natural products or bioactive compounds from plants such as maceration, Soxhlet extraction, supercritical fluid extraction, ultrasound-assisted extraction, ultrasonic-assisted extraction, microwave-assisted extraction, subcritical water extraction, supercritical carbon dioxide extraction and high-pressure processing. However, extracted yields and compounds also depend on the solvent used for extraction and are not solely focused on the method. (Do et al., 2014). The extraction solvent is one of the crucial factors affecting the extraction efficiency of bioactive compounds from plant materials. The selection of solvent extraction is dependent on the purpose of the extraction such as type of analysis, the physicochemical properties of the matrix, the nature of targeted compounds, the availability of the reagents and equipment, safety concerns and price of the solvent ( $\mathrm{Yu}$ et al., 2002). Organic solvents are selected based on higher density rather than water, extraction ability of selected compounds, and good gas chromatography performance.

This review built in three main themes focused on extraction solvents, which are methanol, ethanol and water used in extracting agarwood and its parts (Table 3 ). Because natural bioactive compounds have many benefits in medicine and health, the extraction process will be optimized to obtain these beneficial bioactive compounds. A previous study reported that agarwood contains extensive aromatic compounds, mainly sesquiterpenes and phenylethyl chromone derivatives (Chen et al., 2012). These compounds are indicators to determine the quality of the agarwood, particularly resulting from synthetic inoculation process.

\subsection{Methanol}

A total of three studies obtained from PRISMA analysis from Scopus database used methanol as a solvent in extracting agarwood parts Study 1 (Suzuki et al., 2017), Study 2 (Huo et al., 2018) and Study 3 (Jayaraman and Mohamed, 2015)). Methanol is often being used as an extraction solvent since aqueous methanol was more effective in extracting total phenolics and antioxidative components compared to water (Zhou and $\mathrm{Yu}, 2004)$. In general, methanol has been discovered to be more efficient in the extraction of polyphenols, which have lower molecular weight (Do et al., 2014). Study 1 and Study 2 used methanol in extracting the agarwood and isolated some selected compounds from the crude methanolic extract. Meanwhile, Study 3 used methanol to extract dry cell of agarwood that harvested from tissue culture. Jayaraman and Mohamed (2015) were developed plant tissue culture from agarwood leaves cell for rapid mass production to regenerate agarwood plant and produce secondary metabolites from the plant such as aromatic compounds.

Suzuki et al. (2017) extracted powdered Aquilaria filaria heartwood with 95\% methanol (room temperature, $72 \mathrm{hr}$ ). From the crude methanolic extract, 11 compounds have been isolated namely, 2-(2-hydroxy -2-phenylethyl)chromone, 6-hydroxy-7-methoxy-2-[2-(4 -methoxyphenyl)ethyl]chromone, 8-chloro-6-hydroxy-2(2-phenylethyl)chromone, 6-hydroxy-7-methoxy-2-(2-

Table 3. Thematic analysis

\begin{tabular}{|c|c|c|c|c|}
\hline \multirow{2}{*}{ Article } & \multirow{2}{*}{ Species } & \multicolumn{3}{|c|}{ Solvent } \\
\hline & & Methanol & Ethanol & Water \\
\hline Suzuki et al. (2017) & Aquilaria filaria & $\sqrt{ }$ & & \\
\hline Huo et al. (2018) & Aquilaria sinensis & $\sqrt{ }$ & & \\
\hline Jayaraman and Mohamed (2015) & Aquilaria malaccensis & $\sqrt{ }$ & & \\
\hline Lee et al. (2018) & Aquilariae lignum & & $\sqrt{ }$ & \\
\hline Lio et al. (2016) & Aquilaria sinensis & & $\sqrt{ }$ & \\
\hline Dong et al. (2019) & Gyrinops salicifolia & & $\sqrt{ }$ & \\
\hline Manoka et al. (2016) & Aquilaria crassna & & & $\sqrt{ }$ \\
\hline
\end{tabular}


phenylethyl)chromone, 6,7-dimethoxy-2-(2-phenylethyl) chromone, 6-hydroxy-2-[2-(4-methoxyphenyl)ethyl] chromone, 6-hydroxy-2-[2-(4-hydroxyphenyl)ethyl] chromone, 6-hydroxy-2-(2-phenylethyl)chromone, 8hydroxy-2-(2-phenylethyl)chromone, 6,8-dihydroxy-2-(2 -phenylethyl)chromone, and 2-(2-phenylethyl)chromone. These isolated chromones were tested for antiproliferative activity against human tumor cell lines and antitumor promoting effects. The results have mentioned that all 11 chromones inhibit tumor promotion at noncytotoxic concentrations.

Agarwood has been used as herbal medicine in certain countries; however, the quality of agarwood was unidentified. Therefore Huo et al. (2018) were carried out quality evaluation techniques for Chinese agarwood (Aquilaria sinesis) and other herbal medicines to guarantee the clinical therapeutic outcomes as well as the economic values. Several relevant materials of Aquilaria sinensis, such as fruits, stems, leaves, callus and $\mathrm{NaCl}$ stimulated callus were pooled and extracted with methanol for $30 \mathrm{~min}$ in an ultrasonic-assisted manner. Later the extract was fractionated to afford some fractions. From the study, authentic compound-free quantification was achieved for eight 2-(2-phenylethyl) chromone derivatives from Chinese agarwood.

Interestingly, cell culture technique has been used by Study 3 to produce the aroma of agarwood in the laboratory. Jayaraman and Mohamed (2015) were established a cell suspension culture of Aquilaria malaccensis from leaf-derived callus and used a fungal elicitor to induce agarwood production in the culture. Cell suspension cultures were treated with Trichoderma extract; a fungal elicitor to increase fragrance intensity comparable to the aroma of agarwood. Then, the cell culture was harvested and extracted in methanol in a Soxhlet apparatus for $5 \mathrm{hrs}$. GC-MS analysis detected several important agarwood compounds from the extract. Although mild agarwood aroma was detected from the elicited samples, there are no major agarwood compounds detected in these samples. Interestingly, several agarwood compounds were detected from the cell suspension culture that emitted the scent.

\subsection{Ethanol}

Ethanol also is a polar solvent and has been known as a suitable solvent for polyphenol extraction and is non -toxic for human consumption. It has some advantages which make it widely used for extraction such as low cost, adequate boiling point and strong ability to penetrate plant cells. Most organic compounds can be dissolved in ethanol except protein, phlegm, pectin, starch and polysaccharide (Xu et al., 2011). There are three studies that use ethanol as the extraction solvent which are Study 4 (Liao et al., 2016), Study 5 (Lee et al., 2018) and Study 6 (Dong et al., 2019). All studies have performed the isolation for targeted compounds from the ethanol extract of agarwood to test the pharmacological effects of certain diseases in vitro.

In Study 4, the agarwood (Aquilaria sinesis) was crushed and then refluxed with 95\% ethanol. Fifteen 2-(2 -phenylethyl) chromone derivatives were isolated from the ethanolic extract of $A$. sinesis (Liao et al., 2016). The compounds were assessed for $\alpha$-glucosidase inhibitory activity, AchE inhibitory activity and cytotoxic activity against BEL-7402, K562, and SGC-7901 human cancer cell lines. The study also revealed that 6,7-dimethoxy-2[2-(4-hydroxyphenyl)ethyl] chromone, 6,7-dihydroxy-2[2-(4-methoxyphenyl)ethyl] chromone and 6-hydroxy-2[2-(3-methoxy-4-hydroxyphenyl)ethyl] chromone obviously inhibited against $\alpha$-glucosidase in vitro. Nonetheless 6, 8-dihydroxy-2-[2-(4-methoxyphenyl) ethyl] chromone, 6,7-dimethoxy-2-[2-(3-hydroxy-4methoxyphenyl)ethyl] chromone, 6-hydroxy-7-methoxy2-[2-(3-hydroxy-4-methoxyphenyl)ethyl] chromone and 6-hydroxy-2-[2-(3-methoxy-4-hydroxyphenyl)ethyl] chromone showed weak inhibitory activity against AchE. Meanwhile 6,7-dihydroxy-2-[2-(4-methoxyphenyl)ethyl] chromone and 6-methoxy-7-hydroxy-2-[2-(4methoxyphenyl)ethyl] chromone demonstrated weak cytotoxicity against human gastric cell line (SGC-7901).

Study 5 was done by investigating the pharmacological effect of Aquilaria lignum against glutamate-induced neuroexcitotoxicity and its underlying mechanisms using HT22 cells, a mouse hippocampal neuron cell line (Lee et al., 2018). A. lignum resinous heartwood was extracted using 30\% ethanol for $72 \mathrm{~h}$. Ultra-high-performance liquid chromatography-tandem mass spectrometry (UHPLC-MS/MS) was conducted on A. lignum extract to determine its chemical composition (Lee et al., 2017). The identified chemical formula was assumed to be $\mathrm{C}_{10} \mathrm{H}_{12} \mathrm{O}_{3} \mathrm{~N}$ (ferulamide), $\mathrm{C}_{17} \mathrm{H}_{18} \mathrm{O}_{5} \mathrm{~N}$ (benzyloxycarbonyl-L-tyrosine), $\mathrm{C}_{17} \mathrm{H}_{16} \mathrm{O}_{4} \mathrm{~N}$ (Fmoc-Lglycine), $\mathrm{C}_{18} \mathrm{H}_{20} \mathrm{O}_{5} \mathrm{~N}$ (carbobenzoxy-O-benzyl-L-serine), $\mathrm{C}_{18} \mathrm{H}_{18} \mathrm{O}_{4} \mathrm{~N}$ (Fmoc-L-alanine or Fmoc-Sarcosine), $\mathrm{C}_{17} \mathrm{H}_{18} \mathrm{O}_{4} \mathrm{~N}$ (carbobenzyloxyphenylalanine), $\mathrm{C}_{34} \mathrm{H}_{33} \mathrm{O}_{8} \mathrm{~N}_{2}$ or $\mathrm{C}_{21} \mathrm{H}_{41} \mathrm{O}_{19}$ (unknown), and $\mathrm{C}_{18} \mathrm{H}_{20} \mathrm{O}_{4} \mathrm{~N}$ (transferuloyltyramine). The result confirmed the neuroprotective properties of A. Lignum on glutamateinduced hippocampal neuron excitotoxicity.

In Study 6, three compounds of Gyrinops salicifolia Ridl. extract was isolated and tested on acetylcholinesterase (AchE) inhibitory activity and cytotoxic activity against human myeloid leukaemia cell line (K562) (Dong et al., 2019). Gyrinops salicifolia Ridl. (Thymelaeaceae) is one of agarwood-producing 
endemic species in Papua New Guinea. The resinous heartwood of $G$. salicifolia was extracted with $95 \%$ ethanol at heating reflux and then extracted with ethyl acetate and n-butanol before fractionated and led to the isolation of three 2-(2-phenylethyl)chromone derivatives (Gyrinone A, Gyrinone B and 5-hydroxy-2-[2-(3hydroxy-4-methoxyphenyl)ethenyl]chromone) which were elucidated as novel structures. Addition to that, the result has also reported that there was no inhibition effect on AchE inhibitory activity or cytotoxicity against K562 cell line.

\subsection{Water}

Some researchers use water as extraction solvent because aqueous extraction offers numerous advantages over conventional solvent extractions such as low cost, safe, and capability of tunable their properties by changing the temperature (Plaza and Turner, 2015). However, extraction by water may also yield more salt, protein, sugar and starch and make the purification process more challenging (Xu et al., 2011). From this review, only one study used water as an extraction solvent to produce Aquilaria crassna leaves aqueous extract (Manoka et al., 2016). Dried powdered leaves were extracted in boiling water for $15 \mathrm{~min}$. The extract was analysed for antioxidant and hypoglycaemic activities in vitro and in vivo using streptozotocin (STZ)nicotinamide (NA)-induced type 2 diabetic mice. The result showed that $A$. crassna extract significantly lowered the blood glucose level. However, the expression of GLUT4 in skeletal muscle was not significantly changed with the extract. GLUT4 is the insulin-regulated glucose transporter found primarily in skeletal and cardiac muscle, and adipose tissues.

\section{Conclusion}

The application of adequate extraction solvents guarantees the target compounds to be extracted and avoids the interference of other unnecessary components. Limited studies have projected different extracting solvents that have been used in different methods of agarwood extraction. Methanol, ethanol and water have their own role in extracting agarwood and its parts, particularly for pharmacological or nutraceutical purposes. Methanol and ethanol regularly have been used in agarwood extraction before the extract partitioned to isolate targeted compounds. Even the use of water in extraction is cost-effective and safe compared to other solvents, the aqueous extract usually did not partition because it may have more impurities which make the separation process tough.

\section{Conflict of Interest}

Authors declare no conflict of interest.

\section{Acknowledgments}

The authors wish to thank The Universiti Tun Hussien Onn Malaysia under Geran Penyelidikan Pasca Siswazah (GPPS Vot No. H415) and UTHM RMC Research Fund (Vot E15501) for supporting this research.

\section{References}

Azren, P.D., Lee, S.Y., Emang, D. and Mohamed, R. (2019). History and perspectives of induction technology for agarwood production from cultivated Aquilaria in Asia: a review. Journal of Forestry Research, 30(1), 1-11. https://doi.org/10.1007/ s11676-018-0627-4

Barden, A., Anak, N. A., Mulliken, T. and Song, M. (2000). Heart of the matter: agarwood use and trade and CITES implementation for Aquilaria malaccensis. Cambridge, UK: TRAFFIC International.

Chen, H.Q., Wei, J.H., Yang, J.S., Zhang, Z., Yang, Y., Gao, Z.H., Sui, C. and Gong, B. (2012). Chemical constituents of agarwood originating from the endemic genus Aquilaria plants. Chemistry and Biodiversity, 9(2), 236-250. https://doi.org/10.1002/ cbdv.201100077

Do, Q.D., Angkawijaya, A.E., Tran-Nguyen, P.L., Huynh, L.H., Soetaredjo, F.E., Ismadji, S. and Ju, Y. -H. (2014). Effect of extraction solvent on total phenol content, total flavonoid content, and antioxidant activity of Limnophila aromatica. Journal of Food and Drug Analysis, 22(3), 296-302. https://doi.org/10.1016/j.jfda.2013.11.001

Dong, W.-H., Wang, H., Guo, F.-J., Mei, W.-L., Chen, H.-Q., Kong, F.-D., Li, W., Zhou, K.-B. and Dai, H.F. (2019). Three New 2-(2-Phenylethyl) chromone Derivatives of Agarwood Originated from Gyrinops salicifolia. Molecules, 24(3), 576. https:// doi.org/10.3390/molecules24030576

Hara, H., Ise, Y., Morimoto, N., Shimazawa, M., Ichihashi, K., Ohyama, M. and Iinuma, M. (2008). Laxative effect of agarwood leaves and its mechanism. Bioscience, Biotechnology, and Biochemistry, 72(2), 335-345. https:// doi.org/10.1271/bbb.70361

Hashim, Y.Z. H.-Y., Kerr, P.G., Abbas, P. and Salleh, H.M. (2016). Aquilaria spp.(agarwood) as source of health beneficial compounds: A review of traditional use, phytochemistry and pharmacology. Journal of 
Ethnopharmacology, 189, 331-360. https:// doi.org/10.1016/j.jep.2016.06.055

Hendra, H., Moeljopawiro, S. and Nuringtyas, T.R. (2016). Antioxidant and antibacterial activities of agarwood (Aquilaria malaccensis Lamk.) leaves. In Nurngtyas, T.R., Roto, R., Widyaparaga, A., Mahardika, M., Kusumaadmaja, A. and Hadi, N. (Eds.) Advances of Science and Technology for society: Proceedings of the $1^{\text {st }}$ International Conference on Science and Technology 2015 (ICST2015). Vol. 1755. AIP Conference Proceedings. Ebook.

Huo, H., Liu, Y., Liu, W., Sun, J., Zhang, Q., Zhao, Y., Zheng, J., Tu, P., Song, Y. and Li, J. (2018). A full solution for multi-component quantification-oriented quality assessment of herbal medicines, Chinese agarwood as a case. Journal of Chromatography A, 1558, 37-49. https://doi.org/10.1016/ j.chroma.2018.05.018

Ismail, N., Ali, N.A.M., Jamil, M., Rahiman, M.H.F., Tajuddin, S.N. and Taib, M.N. (2014). A review study of agarwood oil and its quality analysis. Jurnal Teknologi, 68(1), 37-42. https://doi.org/10.11113/ jt.v68.2419

Ismail, N., Rahiman, M.H.F., Taib, M.N., Ibrahim, M., Zareen, S. and Tajuddin, S.N. (2015). A review on agarwood and its quality deteremination presented at the 2015 IEEE 6th Control and System Graduate Research Colloquium (ICSGRC)IEEE, p. 103-108. Shah Alam, Malaysia: IEEE.

Jayaraman, S. and Mohamed, R. (2015). Crude extract of Trichoderma elicits agarwood substances in cell suspension culture of the tropical tree, Aquilaria malaccensis Lam. Turkish Journal of Agriculture and Forestry, 39(2), 163-173. https:// doi.org/10.3906/tar-1404-63

Kakino, M., Izuta, H., Ito, T., Tsuruma, K., Araki, Y., Shimazawa, M., Oyama, M., Iinuma, M. and Hara, H. (2010a). Agarwood induced laxative effects via acetylcholine receptors on loperamide-induced constipation in mice. Bioscience, Biotechnology, and Biochemistry, 74(8), 1550-1555. https:// doi.org/10.1271/bbb.100122

Kakino, M., Tazawa, S., Maruyama, H., Tsuruma, K., Araki, Y., Shimazawa, M. and Hara, H. (2010b). Laxative effects of agarwood on low-fiber dietinduced constipation in rats. BMC Complementary and Alternative Medicine, 10, 68. https:// doi.org/10.1186/1472-6882-10-68

Khalil, A., Rahim, A., Taha, K. and Abdallah, K. (2013). Characterization of methanolic extracts of agarwood leaves. Journal of Applied and Industrial Sciences, 1 (3), 78-88.
Lee, H.-Y., Lee, J.-S., Kim, H.-G., Kim, W.-Y., Lee, S.B., Choi, Y.-H. and Son, C.-G. (2017). The ethanol extract of Aquilariae Lignum ameliorates hippocampal oxidative stress in a repeated restraint stress mouse model. BMC complementary and alternative medicine, 17, $397 . \quad \mathrm{https} / / /$ doi.org/10.1186/s12906-017-1902-1

Lee, J.-S., Kim, W.-Y., Jeon, Y.-J., Lee, S.-K. and Son, C.-G. (2018). Aquilariae Lignum extract attenuates glutamate-induced neuroexcitotoxicity in HT22 hippocampal cells. Biomedicine and Pharmacotherapy, 106, 1031-1038. https:// doi.org/10.1016/j.biopha.2018.07.032

Liao, G., Mei, W.-L., Dong, W.-H., Li, W., Wang, P., Kong, F.-D., Gai, C.-J., Song, X.-Q. and Dai, H.-F. (2016). 2-(2-Phenylethyl) chromone derivatives in artificial agarwood from Aquilaria sinensis. Fitoterapia, 110, 38-43. https://doi.org/10.1016/ j.fitote.2016.01.011

Liu, Y.-Y., Wei, J.-H., Gao, Z.-H., Zhang, Z. and Lyu, J. -C. (2017). A review of quality assessment and grading for agarwood. Chinese Herbal Medicines, 9 (1), 22-30. https://doi.org/10.1016/S1674-6384(17) 60072-8

López-Sampson, A. and Page, T. (2018). History of use and trade of agarwood. Economic Botany, 72(1), 107 -129. https://doi.org/10.1007/s12231-018-9408-4

Manoka, S., Sungthong, B., Sato, H., Sugiyama, E. and Sato, V.H. (2016). Hypoglycemic and Antioxidant Activities of the Water Extract of Aquilaria crassna Leaves in Streptozotocin-Nicotinamide-Induced Type-2 Diabetic Mice. Natural Product Communications, 11(6), 757-761.

Naef, R. (2011). The volatile and semi-volatile constituents of agarwood, the infected heartwood of Aquilaria species: a review. Flavour and Fragrance Journal, 26(2), 73-87. https://doi.org/10.1002/ ffj.2034

Okudera, Y. and Ito, M. (2009). Production of agarwood fragrant constituents in Aquilaria calli and cell suspension cultures. Plant Biotechnology, 26(3), 307 -315 . https://doi.org/10.5511/ plantbiotechnology.26.307

Plaza, M. and Turner, C. (2015). Pressurized hot water extraction of bioactives. TrAC Trends in Analytical Chemistry, 71, 39-54. https://doi.org/10.1016/ j.trac.2015.02.022

Pranakhon, R., Pannangpetch, P. and Aromdee, C. (2011). Antihyperglycemic activity of agarwood leaf extracts in STZ-induced diabetic rats and glucose uptake enhancement activity in rat adipocytes. 
Songklanakarin Journal of Science and Technology, 33(4), 405-410.

Suzuki, A., Miyake, K., Saito, Y., Rasyid, F.A., Tokuda, H., Takeuchi, M., Suzuki, N., Ichiishi, E., Fujie, T. and Goto, M. (2017). Phenylethylchromones with in vitro antitumor promoting activity from Aquilaria filaria. Planta medica, 83(3/4), 300-305. https:// doi.org/10.1055/s-0042-110858

$\mathrm{Xu}, \mathrm{R}$., Ye, Y. and Zhao, W. (2011). Introduction to natural products chemistry. USA: CRC press. https:// doi.org/10.1201/b11017

Yu, L., Haley, S., Perret, J., Harris, M., Wilson, J. and Qian, M. (2002). Free radical scavenging properties of wheat extracts. Journal of Agricultural and Food Chemistry, 50(6), 1619-1624. https:// doi.org/10.1021/jf010964p

Zhou, K. and Yu, L. (2004). Effects of extraction solvent on wheat bran antioxidant activity estimation. $L W T$ Food Science and Technology, 37(7), 717-721. https://doi.org/10.1016/j.lwt.2004.02.008 